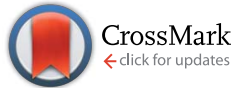

Cite this: Chem. Sci., 2016, 7, 5428

\title{
Guest and solvent modulated photo-driven charge separation and triplet generation in a perylene bisimide cyclophane $\uparrow$
}

\begin{abstract}
Peter Spenst, ${ }^{a}$ Ryan M. Young, ${ }^{b}$ Michael R. Wasielewskib and Frank Würthner ${ }^{* a}$
Cofacial positioning of two perylene bisimide (PBI) chromophores at a distance of $6.5 \AA$ in a cyclophane structure prohibits the otherwise common excimer formation and directs photoexcited singlet state relaxation towards intramolecular symmetry-breaking charge separation ( $\tau_{\mathrm{CS}}=161 \pm 4 \mathrm{ps}$ ) in polar $\mathrm{CH}_{2} \mathrm{Cl}_{2}$, which is thermodynamically favored with a Gibbs free energy of $\Delta G_{\mathrm{CS}}=-0.32 \mathrm{eV}$. The charges then recombine slowly in $\tau_{\mathrm{CR}}=8.90 \pm 0.06 \mathrm{~ns}$ to form the PBI triplet excited state, which can be used subsequently to generate singlet oxygen in $27 \%$ quantum yield. This sequence of events is eliminated by dissolving the PBI cyclophane in non-polar toluene, where only excited singlet state decay occurs. In contrast, complexation of electron-rich aromatic hydrocarbons by the host PBI cyclophane followed by photoexcitation of $\mathrm{PBI}$ results in ultrafast electron transfer ( $<10 \mathrm{ps}$ ) from the guest to the $\mathrm{PBI}$ in $\mathrm{CH}_{2} \mathrm{Cl}_{2}$. The rate constants for charge separation and recombination increase as the guest molecules become easier to oxidize, demonstrating that charge separation occurs close to the peak of the Marcus curve and the recombination lies far into the Marcus inverted region.
\end{abstract}

Received 9th April 2016

Accepted 6th May 2016

DOI: $10.1039 / c 6 s c 01574 c$

www.rsc.org/chemicalscience

challenge with a cyclic perylene bisimide (PBI) trimer for which biomimetic intramolecular symmetry-breaking charge separation (SB-CS) ${ }^{12,17}$ could be observed in $\tau_{\mathrm{CS}}=12 \mathrm{ps}$, although the free energy of charge separation, $\Delta G_{\mathrm{CS}}$, is barely negative. ${ }^{17}$ The charge recombination (CR) back to the PBI ground state (GS) is much slower $\left(\tau_{\mathrm{CR}}=1.12 \mathrm{~ns}\right)$, despite the larger $\Delta G_{\mathrm{CR}}$ of this process. According to Marcus theory, ${ }^{18-20}$ ET can occur in the normal region $\left(-\Delta G_{\mathrm{ET}}<\lambda\right)$ or in the inverted region $\left(-\Delta G_{\mathrm{ET}}>\lambda\right)$ depending on the relative magnitudes of the Gibbs free energy $\left(-\Delta G_{\mathrm{ET}}\right)$ and the reorganization energy $(\lambda) .^{6,21,22}$ The PBI trimer data imply that its charge recombination reaction is in the Marcus inverted region. ${ }^{18-20,23,24}$ Unfortunately, no guest encapsulation could be achieved within the PBI trimer, in contrast to the PBI cyclophane, Cy-PBI, whose fluorescence is quenched by the encapsulation of electron rich aromatic guests. ${ }^{25}$ Accordingly, in the present study we elucidate the electronic interactions of Cy-PBI and its corresponding host-guest complexes by steady-state absorption, fluorescence and transient absorption (TA) spectroscopy to identify the ET processes and the individual lifetimes of the states formed. While Cy-PBI itself fluoresces strongly in low-polarity toluene, it undergoes intramolecular SB-CS followed by CR to the PBI triplet state upon excitation in polar solvents like $\mathrm{CH}_{2} \mathrm{Cl}_{2}$ (Fig. 1). Binding of electron-rich guests within Cy-PBI leads to intermolecular CS followed by CR back to the GS. Thus, the lowest excited singlet state of Cy-PBI decays in a complex sequence of events that can be modulated by solvent polarity or the presence of electronrich guest molecules. 


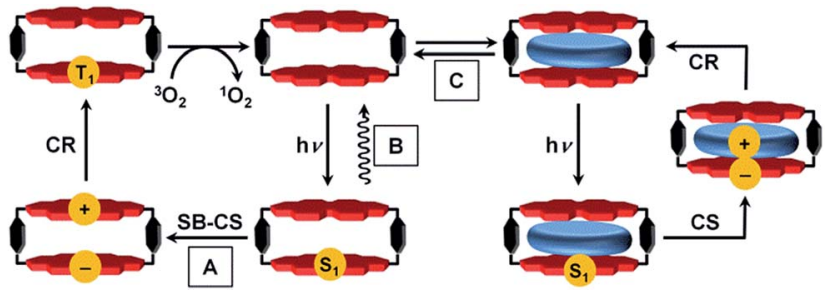

Fig. 1 Schematic of the different excited state photophysics upon excitation; (A) symmetry-breaking charge separation and recombination to the PBI triplet within the PBI cyclophane $\mathrm{Cy}-\mathrm{PBI}$, in $\mathrm{CH}_{2} \mathrm{Cl}_{2}$ that can be used for singlet oxygen generation; (B) emission in toluene: (C) encapsulation of aromatic guests and photo-driven charge separation between guest and $\mathrm{Cy}-\mathrm{PBI}$ and charge recombination to the ground state.

\section{Results and discussion}

\section{Steady state spectroscopy and electrochemistry}

The steady-state UV-vis absorption spectrum of Cy-PBI has its maximum at $582 \mathrm{~nm}$ in $\mathrm{CH}_{2} \mathrm{Cl}_{2}$, which is comparable to the tetraphenoxy-substituted monomeric PBI (Ref-PBI). Similar to other multi-chromophoric PBI systems, the $0-1$ vibronic band of Cy-PBI at $543 \mathrm{~nm}$ is significantly enhanced with respect to the $0-0$ transition that can be related to excitonic coupling of the two cofacial PBI units (Fig. 2a). ${ }^{1,26,27}$ The corresponding fluorescence spectrum has its maximum at $627 \mathrm{~nm}$, which is bathochromically shifted by $12 \mathrm{~nm}$ and has a significantly quenched $7 \%$ fluorescence quantum yield compared to Ref-PBI $\left(\phi_{\mathrm{Fl}}(\right.$ Ref-PBI $)=75 \%$ in $\left.\mathrm{CH}_{2} \mathrm{Cl}_{2}\right)$, indicative of an efficient
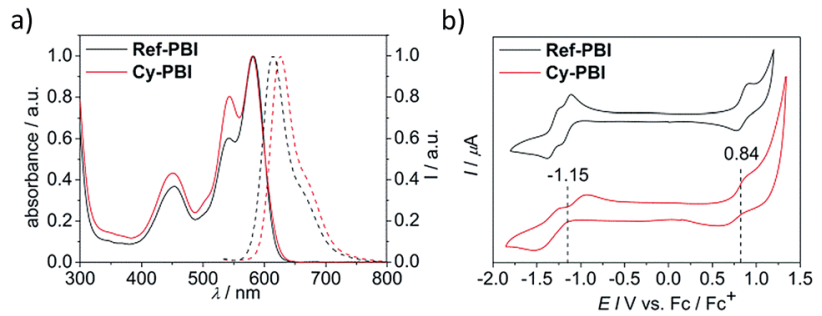

c)
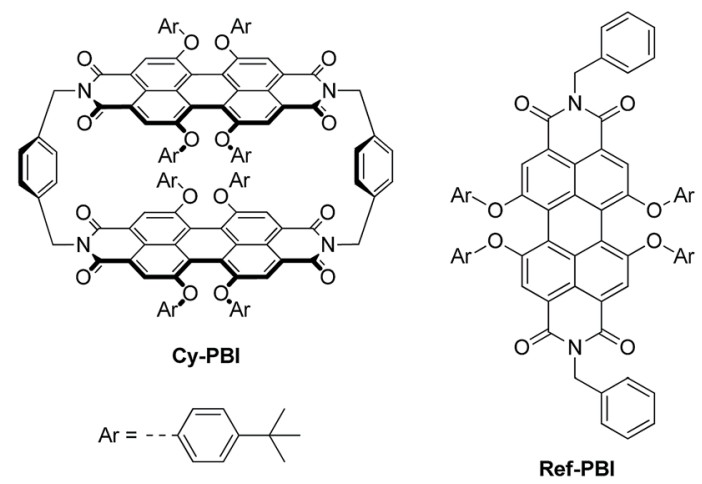

Fig. 2 Normalized UV-vis absorption (solid line) and fluorescence (dashed line) spectra (a) of Cy-PBI and Ref-PBI $\left(\mathrm{CH}_{2} \mathrm{Cl}_{2}, \mathrm{RT}, \mathrm{c}=5 \times\right.$ $10^{-5} \mathrm{M}$ ); cyclic voltammograms (b) in $\mathrm{CH}_{2} \mathrm{Cl}_{2}$ (reference electrode: $\mathrm{Ag}$ / $\mathrm{AgCl}$, working and auxiliary electrode: Pt; $0.1 \mathrm{M}$ TBAHFP, Fc ${ }^{+} / \mathrm{Fc}, \mathrm{RT}, \mathrm{C}$ $\sim 2 \times 10^{-4} \mathrm{M}$ ) and chemical structures (c) of Cy-PBI and Ref-PBI. nonradiative decay process. No long-lived and red-shifted excimer-like emission ${ }^{\mathbf{2 6 , 2 7}}$ was observed, which is attributed to the stiff linkage and the relatively long, 6.5 A interplanar distance between the two PBI chromophores.

To calculate the free energy $\Delta G_{\mathrm{CS}}$ we performed cyclic voltammetry on Cy-PBI and Ref-PBI in dry $\mathrm{CH}_{2} \mathrm{Cl}_{2}$ under argon (Fig. 2b). Cy-PBI shows similar behaviour to the monomer with two reversible reduction and one reversible oxidation waves, which are slightly cathodically shifted by $20 \mathrm{mV}$ compared to RefPBI. The broadening of the Cy-PBI voltammogram can be related to multi-electron processes. ${ }^{26}$ To quantify $\Delta G_{\mathrm{CS}}$ and $\Delta G_{\mathrm{CR}}$ for the cyclophane we applied the Weller equation (eqn (1) and (2)): ${ }^{28}$

$$
\begin{gathered}
\Delta G_{\mathrm{CS}}=e\left[E_{\mathrm{ox}(\mathrm{D})}-E_{\mathrm{red}(\mathrm{A})}\right]-E_{00} \\
-\frac{e^{2}}{4 \pi \varepsilon_{0} \varepsilon_{\mathrm{s}} r_{\mathrm{DA}}}-\frac{e^{2}}{8 \pi \varepsilon_{0}}\left(\frac{1}{r_{\mathrm{D}}}+\frac{1}{r_{\mathrm{A}}}\right)\left(\frac{1}{\varepsilon_{\mathrm{ref}}}-\frac{1}{\varepsilon_{\mathrm{s}}}\right) \\
\Delta G_{\mathrm{CR}}=-\left(\Delta G_{\mathrm{CS}}+E_{00}\right)
\end{gathered}
$$

where $E_{\mathrm{Ox}(\mathrm{D})}$ and $E_{\mathrm{red}(\mathrm{A})}$ are the first oxidation and reduction potentials of PBI, respectively, $E_{00}$ is the excited state energy, $r_{\mathrm{DA}}$ is donor-acceptor center-to-center distance, and $r_{\mathrm{D}}$ and $r_{\mathrm{A}}$ are the effective ionic radii, respectively. The dielectric constants of the spectroscopic solvent and of the solvent used in electrochemistry are given with $\varepsilon_{\mathrm{s}}$ and $\varepsilon_{\text {ref }}$. Since we used $\mathrm{CH}_{2} \mathrm{Cl}_{2}$ both for the spectroscopy and cyclic voltammetry studies, the Born ionic solvation energy (final) term in the Weller eqn (1) can be neglected. The oxidation and reduction potentials are $0.84 \mathrm{~V}$ and $-1.15 \mathrm{~V}$ vs. $\mathrm{Fc}^{+} / \mathrm{Fc}$, the excited state energy calculated from the average value of absorption and emission maxima of Cy-PBI is $2.06 \mathrm{eV}$, and the $0.65 \mathrm{~nm}$ distance between the two PBI units in Cy-PBI is obtained from the DFT calculated structure. Thus, the Gibbs free energy for intramolecular charge separation and recombination in Cy-PBI is calculated to $\Delta G_{\mathrm{CS}}=-0.32 \mathrm{eV}$ and $\Delta G_{\mathrm{CR}}=-1.74 \mathrm{eV}$, respectively, confirming that both electron transfer processes are thermodynamically favorable.

\section{Transient absorption spectroscopy of the free host Cy-PBI}

To elucidate the excited state dynamics in Cy-PBI, we performed femtosecond (fs) and nanosecond (ns) TA studies (Fig. 3, S3 and $\mathrm{S} 4 \dagger$ in the ESI $\dagger$ ). The fs TA spectra (Fig. 3a) show the ground state bleach (GB) at 461,543 and $583 \mathrm{~nm}$ and the stimulated emission (SE) at 611 and $664 \mathrm{~nm}$ as shoulders in the spectra. The excited singlet state ${ }^{1 *} \mathrm{PBI}$ absorption (ESA) has a positive signal at $710 \mathrm{~nm}$ and two characteristic strong maxima in the NIR region at 959 and $1035 \mathrm{~nm}$. While the TA spectra and high fluorescence quantum yield for ${ }^{1}$ *Ref-PBI indicate that it decays back to the ground state primarily by emission (Fig. S2 $\uparrow$ ), Cy-PBI shows very different excited state dynamics with a fast decay of the ${ }^{1 *}$ PBI state in $161 \pm 4$ ps to a new transient species. Here the SE and ESA signals fully disappear, while new bands arise in the visible region at 486 and $628 \mathrm{~nm}$, in the NIR region at 797, 993 and $1100 \mathrm{~nm}$ with a broad feature at $\sim 1220 \mathrm{~nm}$.

By comparison to the PBI radical cation and anion absorption spectra these bands can clearly be attributed to $\mathrm{PBI}^{{ }^{+}}$ $(486,628,1220 \mathrm{~nm})$ and $\mathrm{PBI}^{\cdot-}(797,993,1100 \mathrm{~nm}) .{ }^{17,29}$ From 


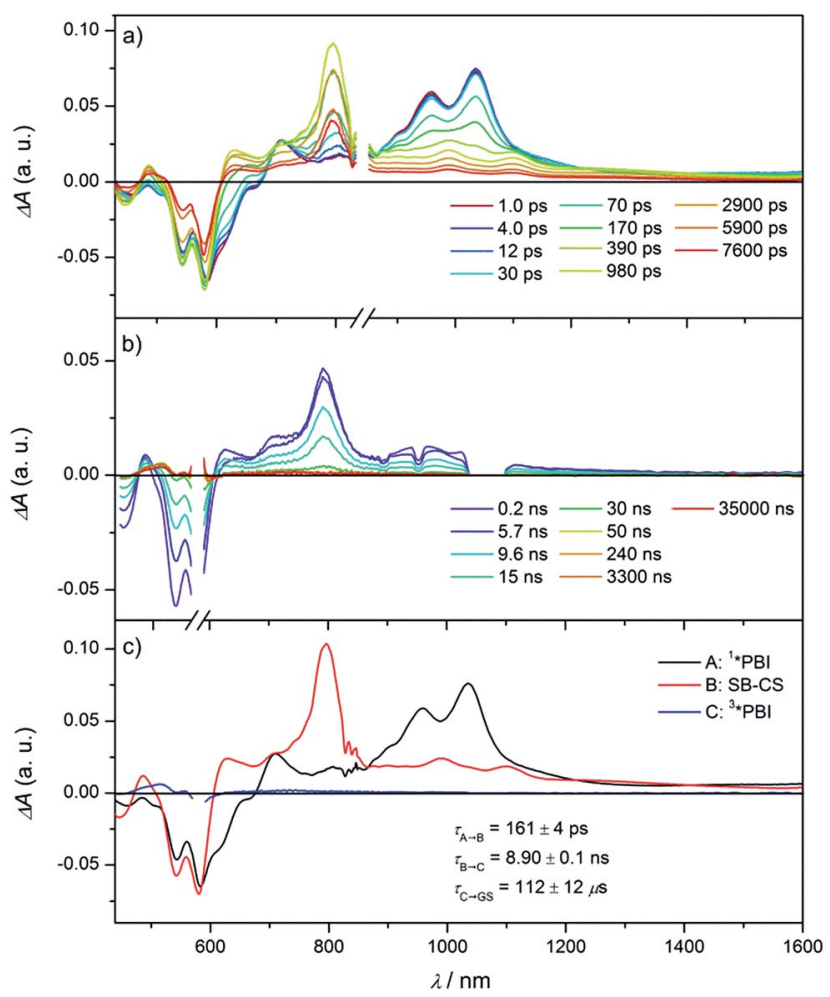

Fig. 3 Femtosecond (a) and nanosecond (b) transient absorption spectra of $\mathrm{Cy}-\mathrm{PBI}$ in $\mathrm{CH}_{2} \mathrm{Cl}_{2}$ showing the excited state dynamics after photoexcitation. Species-associated spectra (c) reconstructed from global fits to the sequential $\mathrm{A} \rightarrow \mathrm{B} \rightarrow \mathrm{C} \rightarrow$ ground state model, where $A$ is ${ }^{1} * \mathrm{PBI}, \mathrm{B}$ is SB-CS state and $\mathrm{C}$ is ${ }^{3} * \mathrm{PBI}\left(\lambda_{\text {ex }}=580 \mathrm{~nm}, 1.0 \mu \mathrm{J}\right.$ per pulse, $\mathrm{CH}_{2} \mathrm{Cl}_{2}, 298 \mathrm{~K}$, degassed for ns TA). The $\mathrm{C} \rightarrow$ ground state time was determined from ns TA.

these ultrafast transient dynamics data we conclude that photodriven intramolecular SB-CS occurs in Cy-PBI with a high quantum yield.

Most interestingly and presumably caused by the long distance between the PBI moieties, $\mathrm{CR}$ between $\mathrm{PBI}^{\circ+}$ and $\mathrm{PBI}^{-}$ in Cy-PBI occurs only slowly with $8.90 \pm 0.06 \mathrm{~ns}$ to produce a significant yield of the PBI triplet state $\left({ }^{3 *} \mathrm{PBI}\right)$ characterized by positive absorptions at 515 and $556 \mathrm{~nm}$, a bleach at $579 \mathrm{~nm}$ and a weak positive and broad absorption at $734 \mathrm{~nm}$ (Fig. 3b). ${ }^{30}$

\section{Triplet formation mechanism}

Spin-orbit induced intersystem crossing (SO-ISC) is slow in PBIs, leading to very low triplet quantum yields for common PBIs $(<1 \%){ }^{31-33}$ Since formation of $\mathrm{PBI}^{+{ }^{+}-\mathrm{PBI}^{-}}{ }^{-}$is a prerequisite for populating ${ }^{3 *} \mathrm{PBI}$, either spin-orbit charge transfer intersystem crossing (SOCT-ISC) or radical pair intersystem crossing (RP-ISC) are responsible for ${ }^{3 *}$ PBI formation. ${ }^{30}$ The SOCT-ISC mechanism requires large changes in orbital angular momentum upon formation of $\mathrm{PBI}^{+\cdot}-\mathrm{PBI}^{-}$, which would require the $\pi$ systems of the two PBI molecules to be nearly orthogonal, ${ }^{34-36}$ which is not the case in Cy-PBI. In contrast, the RP-ISC mechanism requires a relatively weak magnetic interaction between the two PBI radicals within $\mathrm{PBI}^{+}-\mathrm{PBI}^{-\cdot} \cdot{ }^{37,38}$ Photoexcitation of $\mathbf{C y}$-PBI produces ${ }^{1}\left(\mathrm{PBI}^{+}{ }^{+}-\mathrm{PBI}^{-}{ }^{-}\right)$, whose spin dynamics depend strongly on the isotropic spin-spin exchange interaction, $2 J=E_{\mathrm{S}}-E_{\mathrm{T}}$, where $E_{\mathrm{S}}$ and $E_{\mathrm{T}}$ are the energies of ${ }^{1}\left(\mathrm{PBI}^{+}{ }^{+}-\mathrm{PBI}^{-}{ }^{-}\right)$and ${ }^{3}\left(\mathrm{PBI}^{+}{ }^{+}-\mathrm{PBI}^{-}\right)$, respectively. ${ }^{39}$ Due to the long through-space and through-bond distances between the PBI subunits, $2 J$ for $\mathrm{PBI}^{+\cdot}-\mathrm{PBI}^{-\cdot}$ should be small enough to enable RP-ISC of ${ }^{1}\left(\mathrm{PBI}^{+\cdot}-\mathrm{PBI}^{-\cdot}\right)$ to ${ }^{3}\left(\mathrm{PBI}^{+\cdot}-\mathrm{PBI}^{-\cdot}\right) \cdot \cdot^{37,38}$ Moreover, since $2 J \propto V^{2},{ }^{39}$ and $k_{\mathrm{ET}} \propto V^{2}$ (eqn (3)), the relatively long $8.90 \mathrm{~ns} \mathrm{CR}$ time is also consistent with a small value of $2 J$. The subsequent CR process is spin selective in that ${ }^{1}\left(\mathrm{PBI}^{+\cdot}-\mathrm{PBI}^{-\cdot}\right)$ recombines back to the singlet ground state, whereas ${ }^{3}\left(\mathrm{PBI}^{+\cdot}-\mathrm{PBI}^{-\cdot}\right)$ recombines to ${ }^{3 *}$ PBI within $\mathbf{C y}$-PBI. ${ }^{40}$ Our experimental findings, thus, indicate that RP-ISC is the most likely mechanism producing ${ }^{3 *}$ PBI within Cy-PBI. Unfortunately, the $8.90 \mathrm{~ns}$ $\mathrm{PBI}^{+\cdot}-\mathrm{PBI}^{-\cdot}$ lifetime is too short to observe this RP directly by time-resolved EPR spectroscopy.

The lifetime of ${ }^{3 *}$ PBI within Cy-PBI is very long $(\tau \geq 112 \mu \mathrm{s})$ in a degassed solution at room temperature. Isolating $\mathbf{C y - P B I}$ in a glassy solvent matrix is necessary to prohibit quenching by diffusion; however, this also prohibits the SB-CS process and thus, the intrinsic triplet lifetime could not be investigated. To estimate the quantum yield for the triplet formation, singlet oxygen emission was measured and compared to that of a methylene blue standard (MB). ${ }^{41}$ From this experiment, the singlet oxygen quantum yield, $\phi_{\Delta}=0.27$, which also serves as the lower limit of the ${ }^{3 *}$ PBI yield, and is consistent with the weak triplet signal in the TA spectra (Fig. 3c). This result and the low fluorescence quantum yield indicate that the main pathway back to the ground state is by singlet RP recombination. Furthermore, no photobleaching of Cy-PBI with singlet oxygen was observed, verifying the great photostability of PBIs against oxidation. The SB-CS process is disfavoured in non-polar solvents such as toluene as evidenced by the increase in Cy-PBI fluorescence quantum yield to $64 \%{ }^{42}$ Consistent with the increased emission, the transient absorption spectra of Cy-PBI in toluene show only singlet excited state decay directly back to the GS in $\tau=4.5 \pm 0.6 \mathrm{~ns}$ without the population of other transient species (Fig. S5†).

\section{Transient absorption spectroscopy of the host-guest complexes}

By adding electron-rich guests, such as carbazole, pyrene, anthracene, and perylene to Cy-PBI, host-guest complexes are formed, leading to a slight bathochromic shift of the Cy-PBI absorption maximum and the appearance of a new band at longer wavelength that can be attributed to a charge transfer transition. Furthermore, the PBI fluorescence is almost fully quenched in the presence of these guests (Fig. S1†). ${ }^{25}$ The oxidation potentials of carbazole, pyrene, anthracene, and perylene are $0.64,{ }^{43} 0.91,{ }^{44} 0.88,{ }^{45}$ and $0.59 \mathrm{~V}^{46}$ vs. $\mathrm{Fc}^{+} / \mathrm{Fc}$, respectively. Using these data, eqn (1), and the calculated 0.35 nm PBI-guest distance in the complex, we calculate $\Delta G_{\mathrm{CS}}=$ $-0.73,-0.46,-0.49$ and $-0.78 \mathrm{eV}$, respectively, and $\Delta G_{\mathrm{CR}}=$ $-1.33,-1.60,-1.57$ and $-1.28 \mathrm{eV}$ for the host-guest complexes (guest@Cy-PBI), which clearly show that the electron transfer processes in the complexes are highly favored thermodynamically. 
In the fsTA spectra, an ultrafast CS components of $\tau_{\mathrm{CS}}=6.7$ $\pm 0.2,3.6 \pm 0.3,1.1 \pm 0.2$ and $0.9 \pm 0.1$ ps were observed for $\mathbf{C y}$ PBI complexed with carbazole, pyrene, anthracene and perylene, respectively (Fig. 4 and S6-S9†). The fsTA spectra of the perylene@Cy-PBI complex in Fig. 4 show the $\mathrm{PBI}^{-}$absorptions along with a strong positive absorption at $542 \mathrm{~nm}$ that can be attributed to perylene ${ }^{+\bullet} \cdot{ }^{47}$ The radical cation features of the other hydrocarbons are much weaker in the observed spectral window and strongly overlap with the GSB and $\mathrm{PBI}{ }^{--}$absorption changes, and were thus not observed. However, no $\mathrm{PBI}^{+} \cdot$ bands were detected, confirming that the CS now takes place between Cy-PBI and the guest molecule alone.

The ultrafast charge separation processes in the complexes are close to our detection limit ( $\sim 200 \mathrm{fs})$; thus the spectra of ${ }^{1 *} \mathrm{PBI}$ are difficult to observe for the perylene and anthracene complexes, but are clearer for pyrene and carbazole. The second time constant gives the CR lifetime directly back to the GS of PBI without any indication of triplet formation. This is consistent with a large $2 J$ in the guest ${ }^{+}{ }^{-}$ $\mathrm{PBI}^{-}$- RP, which precludes RP-ISC. The corresponding CR times using the carbazole, pyrene, anthracene and perylene guests are $\tau_{\mathrm{CR}}=892 \pm 46,593 \pm 42,1140 \pm 120$ to $420 \pm 2 \mathrm{ps}$, respectively.

The data show that the CS rate increases with increasing $\Delta G_{\mathrm{CS}}$ for ET from the HOMO of the respective electron-donating guest to the photo-excited electron-accepting PBI (Fig. 5). Using $\tau_{\mathrm{CS}}$ and $\tau_{\mathrm{CR}}$ obtained from the transient absorption kinetics and the corresponding values of $\Delta G_{\mathrm{CS}}$ and $\Delta G_{\mathrm{CR}}$, the total reorganization energy $\lambda=\lambda_{\mathrm{S}}+\lambda_{\mathrm{I}}$, where $\lambda_{\mathrm{S}}$ and $\lambda_{\mathrm{I}}$ are the solvent and internal reorganization energies, respectively, and the electronic coupling matrix element $V$ can be calculated according to Marcus theory by applying eqn (3): ${ }^{19}$

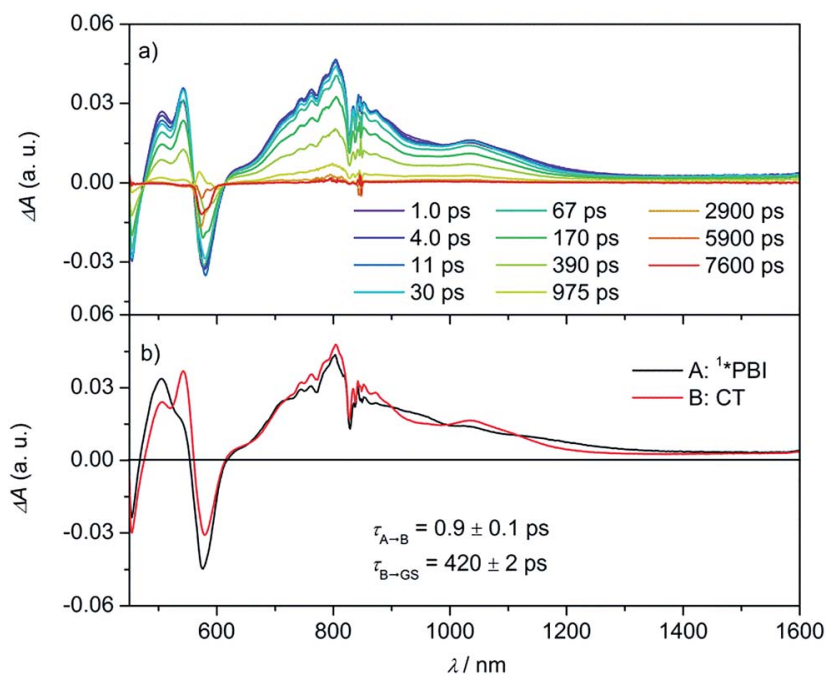

Fig. 4 Femtosecond (a) transient absorption spectra of the peryleneaCy-PBI complex showing the excited state dynamics after photoexcitation. Species-associated spectrum (b) reconstructed from global fits to the sequential $A \rightarrow B \rightarrow$ ground state (GS) model, where $\mathrm{A}$ is ${ }^{1} * \mathrm{PBI}$ and $\mathrm{B}$ is CT state $\left(\lambda_{\text {ex }}=580 \mathrm{~nm}, 1.0 \mu \mathrm{J}\right.$ per pulse, $\mathrm{CH}_{2} \mathrm{Cl}_{2}, 298$ $K$, air equilibrated).

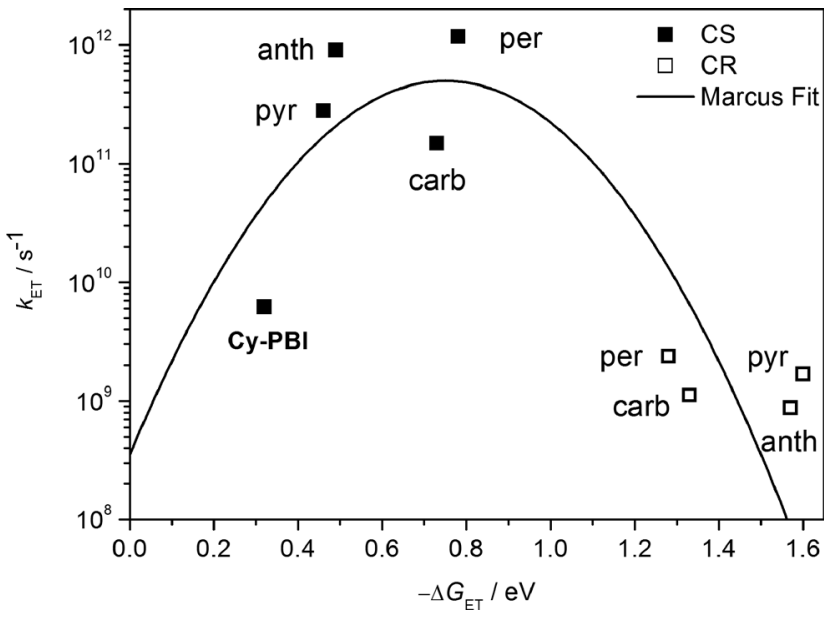

Fig. 5 Plot of electron transfer rate constants in the PBI cyclophane and the corresponding host-guest complexes vs. the thermodynamic driving force $\left(-\Delta G_{E T}\right)$ for charge separation (solid squares) and charge recombination (open squares); the line represents the fit according to eqn (3) with $\lambda=0.75 \mathrm{eV}$ and $V=15 \mathrm{~cm}^{-1}$.

$$
k_{\mathrm{ET}}=\sqrt{\left(\frac{4 \pi^{3}}{h^{2} \lambda k_{\mathrm{B}} T}\right)} V^{2} \exp \left[-\frac{\left(\Delta G_{\mathrm{ET}}+\lambda\right)^{2}}{4 \lambda k_{\mathrm{B}} T}\right]
$$

where $k_{\mathrm{ET}}$ is the electron transfer rate constant calculated from the transient absorption spectra, and $\Delta G_{\mathrm{ET}}$ is the Gibbs free energy for charge separation or recombination. Given that the difference in $\lambda$ between the GS and the excited singlet state for rigid aromatic molecules like PBI is very small, a single curve is drawn through both the CS and CR data, even though, strictly speaking, they represent two different reactions: (1) excited singlet state $\rightarrow$ RP and (2) RP $\rightarrow$ GS. The experimental data of $k_{\mathrm{ET}}$ were fitted by eqn (3), giving a reorganization energy $\lambda=0.75$ $\mathrm{eV}$ and an electronic coupling matrix element $V=15 \mathrm{~cm}^{-1}$. The relatively high value of $\lambda$ is consistent with a large $\lambda_{\mathrm{S}}$ resulting from reorientation of polar $\mathrm{CH}_{2} \mathrm{Cl}_{2}$ in response to the formation or decay of the RP charges. ${ }^{7}$ Furthermore, the data show that the CS lies in the Marcus normal region and reaches the peak of the Marcus parabola for the perylene@Cy-PBI complex, where $-\Delta G_{\mathrm{ET}} \cong \lambda$. In contrast, the CR lies far in the Marcus inverted region, where the ET rates decrease with increasing free energy changes. The slow recombination observed in the Marcus inverted region is in general considered advantageous because long-lived charge separated states offer the possibility to utilize their stored energy for desired purposes such as artificial photosynthesis. ${ }^{\mathbf{1 - 4 , 6 , 7 , 9 - 1 1}}$

\section{Conclusions}

In summary, we have shown that the PBI cyclophane Cy-PBI undergoes intramolecular symmetry-breaking charge separation and slow charge recombination, which is accompanied by RP-ISC leading to ${ }^{3 *} \mathrm{PBI}$ that can be used to generate singlet oxygen with a $27 \%$ quantum yield.

Since ${ }^{3 *} \mathrm{PBI}$ is not accessible by conventional SO-ISC, ${ }^{48}$ the RP-ISC pathway to ${ }^{3 *} \mathrm{PBI}$ offers the possibility of developing an 
entirely new set of PBI applications, as demonstrated here with singlet oxygen generation. In contrast, the CS reaction within Cy-PBI is endergonic in a non-polar solvent like toluene, resulting in a high $\mathbf{C y}$-PBI fluorescence quantum yield. Binding electron-rich guest molecules within the Cy-PBI host affords a complete change of the photoexcited state relaxation pathway leading to intermolecular charge separation within a few picoseconds with formation of the radical cation of the guest and the PBI radical anion. Our findings show that the PBI cyclophane is indeed a special dye pair whose excited state properties are effectively modulated by its solvent environment as well as host-guest complex formation with electron donors.

\section{Experimental methods}

\section{Synthesis}

The tetraphenoxy-substituted perylene bisimide cyclophane (Cy-PBI) and the monomeric reference compound (Ref-PBI) were prepared according to literature. ${ }^{25}$

\section{Steady-state spectroscopy}

UV-vis absorption spectroscopy was performed on a PerkinElmer Lambda 35 or Lambda 950 spectrometer. Solvents for spectroscopic studies were of spectroscopic grade and used without further purification. Fluorescence spectroscopy was performed on a PTI QM-4/2003 spectrofluorimeter. The fluorescence quantum yields were determined by optical dilution $\operatorname{method}^{49}\left(\mathrm{OD}_{\max }<0.05\right)$ as the average value of four different excitation wavelengths using $N, N^{\prime}$-(2,6-di-iso-propylphenyl)1,6,7,12-tetraphenoxyperylen-3,4:9,10-tetracarboxylic acid bisimide ( $\phi_{\mathrm{fl}}=0.96$ in chloroform) as reference. Singlet oxygen emission was recorded on a PTI spectrofluorimeter. The quantum yield of singlet oxygen was determined in an airequilibrated solution of Cy-PBI in dichloromethane $\left(\mathrm{OD}_{\max } \sim\right.$ $0.5)$ as the average value of four different excitation wavelength using methylene blue as reference $\left(\phi_{\Delta}=0.57\right.$ in dichloromethane). ${ }^{41}$

\section{Electrochemistry}

Cyclic voltammetry was carried out with a standard commercial electrochemical analyzer (EC epsilon; BAS Instruments, UK) in a three electrode single-compartment cell. The supporting electrolyte tetrabutylammonium hexafluorophosphate (TBAHFP) was recrystallized from ethanol/water. As an internal standard for the calibration of the potential ferrocenium/ferrocene $\left(\mathrm{Fc}^{+} / \mathrm{Fc}\right)$ was used. As reference electrode $\mathrm{Ag} / \mathrm{AgCl}$ and as working and auxiliary electrodes a Pt disc and a Pt wire were used.

\section{Transient absorption spectroscopy}

Femtosecond and nanosecond transient absorption experiments were performed using an instrument as previously described $^{50}$ with an approximately 120 fs output of a commercial Ti:sapphire oscillator/amplifier (Tsunami/Spitfire, SpectraPhysics) that was split to seed and pump a laboratory-constructed optical parametric amplifier used to generate the 569 nm excitation ("pump") beam and a femtosecond continuum probe, by using a $3 \mathrm{~mm}$ sapphire plate for the visible range or a proprietary crystal for the near-infrared (NIR) spectral region (Ultrafast Systems, LLC). Transient spectra were collected by using customized commercial detectors (Helios, Ultrafast Systems, LLC). Experiments were performed with a depolarized pump to eliminate contributions from orientational dynamics. The kinetic analysis is based on a global fit to selected singlewavelength kinetics. Several kinetic traces at different wavelengths were chosen and fitted globally to a kinetic model. The differential equations were solved and then convoluted with the instrument response function, before employing a least-square fitting to find the parameters which result in matches to the same functions for all selected wavelengths (MATLAB). These parameters are then fed directly into the differential equations, which were solved for the populations of the states in model. Finally, the raw data matrix (with all the raw data) is deconvoluted with the populations as functions of time to produce the species-associated spectra.

\section{Molecular modelling}

DFT calculations were performed by using the Gaussian 09 program package ${ }^{51}$ with $\mathrm{B} 3-\mathrm{LYP}^{52-54}$ as functional and $6-31+\mathrm{G}^{*}$ as basis set. The structures were geometry optimized, followed by frequency calculations on the optimized structures which confirmed the existence of a minimum (one very small imaginary frequency of $4 \mathrm{i} \mathrm{cm}^{-1}$ was obtained for Cy-PBI. Small imaginary frequencies $\left(<100 \mathrm{i} \mathrm{cm}^{-1}\right)$ are considered most likely to be an artefact of the calculation instead of an indication of a transition state ${ }^{55}$ ).

\section{Acknowledgements}

This work has been supported by the DFG in the framework of the research training group FOR 1809 at the Universität Würzburg. Work at Northwestern University was supported by the Chemical Sciences, Geosciences, and Biosciences Division, Office of Basic Energy Sciences, US DOE under grant no. DEFG02-99ER14999 (M. R. W.).

\section{Notes and references}

1 K. N. Ferreira, T. M. Iverson, K. Maghlaoui, J. Barber and S. Iwata, Science, 2004, 303, 1831-1838.

2 T. Weil, T. Vosch, J. Hofkens, K. Peneva and K. Müllen, Angew. Chem., Int. Ed., 2010, 49, 2-28.

3 R. Bhosale, J. Misek, N. Sakai and S. Matile, Chem. Soc. Rev., 2010, 39, 138-149.

4 P. D. Frischmann, K. Mahata and F. Würthner, Chem. Soc. Rev., 2013, 42, 1847-1870.

5 D. Noy, C. C. Moser and P. L. Dutton, Biochim. Biophys. Acta, Bioenerg., 2006, 1757, 90-105.

6 M. R. Wasielewski, M. P. Niemczyk, W. A. Svec and E. B. Pewitt, J. Am. Chem. Soc., 1985, 107, 1080-1082.

7 T. Kircher and H. G. Löhmannsröben, Phys. Chem. Chem. Phys., 1999, 1, 3987-3992. 
8 J. M. Giaimo, A. V. Gusev and M. R. Wasielewski, J. Am. Chem. Soc., 2002, 124, 8530-8531.

9 D. I. Schuster, P. Cheng, P. D. Jarowski, D. M. Guldi, C. Luo, L. Echegoyen, S. Pyo, A. R. Holzwarth, S. E. Braslavsky, R. M. Williams and G. Klihm, J. Am. Chem. Soc., 2004, 126, 7257-7270.

10 J. M. Baumes, J. J. Gassensmith, J. Giblin, J.-J. Lee, A. G. White, W. J. Culligan, W. M. Leevy, M. Kuno and B. D. Smith, Nat. Chem., 2010, 2, 1025-1030.

11 C. C. Hofmann, S. M. Lindner, M. Ruppert, A. Hirsch, S. A. Haque, M. Thelakkat and J. Köhler, J. Phys. Chem. B, 2010, 114, 9148-9156.

12 M. T. Whited, N. M. Patel, S. T. Roberts, K. Allen, P. I. Djurovich, S. E. Bradforth and M. E. Thompson, Chem. Commun., 2012, 48, 284-286.

13 M. H. Schwartz, J. Inclusion Phenom. Mol. Recognit. Chem., 1990, 9, 1-35.

14 M. Brouwer Albert, M. Fazio Sandro, C. Frochot, G. Gatti Francesco, A. Leigh David, K. Y. Wong Jenny and W. H. Wurpel George, Pure Appl. Chem., 2003, 75, 1055-1060.

15 D. M. Bassani, L. Jonusauskaite, A. Lavie-Cambot, N. D. McClenaghan, J.-L. Pozzo, D. Ray and G. Vives, Coord. Chem. Rev., 2010, 254, 2429-2445.

16 M. Kumar, K. V. Rao and S. J. George, Phys. Chem. Chem. Phys., 2014, 16, 1300-1313.

17 Y. Wu, R. M. Young, M. Frasconi, S. T. Schneebeli, P. Spenst, D. M. Gardner, K. E. Brown, F. Würthner, J. F. Stoddart and M. R. Wasielewski, J. Am. Chem. Soc., 2015, 137, 1323613239.

18 R. A. Marcus, J. Chem. Phys., 1956, 24, 966-978.

19 R. A. Marcus, J. Chem. Phys., 1965, 43, 679-701.

20 R. A. Marcus and N. Sutin, Biochim. Biophys. Acta, 1985, 811, 265-322.

21 J. R. Miller, L. T. Calcaterra and G. L. Closs, J. Am. Chem. Soc., 1984, 106, 3047-3049.

22 E. H. A. Beckers, S. C. J. Meskers, A. P. H. J. Schenning, Z. Chen, F. Würthner and R. A. J. Janssen, J. Phys. Chem. A, 2004, 108, 6933-6937.

23 T. Häberle, J. Hirsch, F. Pöllinger, H. Heitele, M. E. MichelBeyerle, C. Anders, A. Döhling, C. Krieger, A. Rückermann and H. A. Staab, J. Phys. Chem., 1996, 100, 18269-18274.

24 A. Osuka, G. Noya, S. Taniguchi, T. Okada, Y. Nishimura, I. Yamazaki and N. Mataga, Chem.-Eur. J., 2000, 6, 33-46.

25 P. Spenst and F. Würthner, Angew. Chem., Int. Ed., 2015, 54, 10165-10168.

26 F. Schlosser, M. Moos, C. Lambert and F. Würthner, Adv. Mater., 2013, 25, 410-414.

27 C. M. Pochas, K. A. Kistler, H. Yamagata, S. Matsika and F. C. Spano, J. Am. Chem. Soc., 2013, 135, 3056-3066.

28 A. Weller, Z. Phys. Chem., 1982, 133, 93-98.

29 F. Würthner, A. Sautter, D. Schmid and P. J. A. Weber, Chem.-Eur. J., 2001, 7, 894-902.

30 D. Veldman, S. M. A. Chopin, S. C. J. Meskers, M. M. Groeneveld, R. M. Williams and R. A. J. Janssen, J. Phys. Chem. A, 2008, 112, 5846-5857.

31 W. E. Ford and P. V. Kamat, J. Phys. Chem., 1987, 91, 63736380.
32 A. A. Rachford, S. Goeb and F. N. Castellano, J. Am. Chem. Soc., 2008, 130, 2766-2767.

33 Y. Wu, Y. Zhen, Y. Ma, R. Zheng, Z. Wang and H. Fu, J. Phys. Chem. Lett., 2010, 1, 2499-2502.

34 M. A. El-Sayed, J. Chem. Phys., 1974, 60, 4502-4507.

35 T. Okada, I. Karaki, E. Matsuzawa, N. Mataga, Y. Sakata and S. Misumi, J. Phys. Chem., 1981, 85, 3957-3960.

36 K. M. Lefler, K. E. Brown, W. A. Salamant, S. M. Dyar, K. E. Knowles and M. R. Wasielewski, J. Phys. Chem. A, 2013, 117, 10333-10345.

37 C. D. Buckley, D. A. Hunter, P. J. Hore and K. A. McLauchlan, Chem. Phys. Lett., 1987, 135, 307-312.

38 M. T. Colvin, A. B. Ricks, A. M. Scott, A. L. Smeigh, R. Carmieli, T. Miura and M. R. Wasielewski, J. Am. Chem. Soc., 2011, 133, 1240-1243.

39 E. A. Weiss, M. J. Ahrens, L. E. Sinks, A. V. Gusev, M. A. Ratner and M. R. Wasielewski, J. Am. Chem. Soc., 2004, 126, 5577-5584.

40 E. A. Weiss, M. A. Ratner and M. R. Wasielewski, J. Phys. Chem. A, 2003, 107, 3639-3647.

41 Y. Usui, Chem. Lett., 1973, 2, 743-744.

42 N. Banerji, G. Angulo, I. Barabanov and E. Vauthey, J. Phys. Chem. A, 2008, 112, 9665-9674.

43 K. Karon and M. Lapkowski, J. Solid State Electrochem., 2015, 19, 2601-2610.

44 J. Daub, R. Engl, J. Kurzawa, S. E. Miller, S. Schneider, A. Stockmann and M. R. Wasielewski, J. Phys. Chem. A, 2001, 105, 5655-5665.

45 V. D. Parker and O. Hammerich, Acta Chem. Scand., Ser. B, 1977, 31, 883-889.

46 B. S. Veldkamp, W.-S. Han, S. M. Dyar, S. W. Eaton, M. A. Ratner and M. R. Wasielewski, Energy Environ. Sci., 2013, 6, 1917-1928.

47 V. V. Danilov, A. S. Panfutova, A. I. Khrebtov, S. Ambrosini and D. A. Videnichev, Opt. Lett., 2012, 37, 3948-3950.

48 F. N. Castellano, Dalton Trans., 2012, 41, 8493-8501.

49 J. R. Lakowicz, Principles of Fluorescence Spectroscopy, New York, 2nd edn, 1999.

50 R. M. Young, S. M. Dyar, J. C. Barnes, M. Juríček, J. F. Stoddart, D. T. Co and M. R. Wasielewski, J. Phys. Chem. A, 2013, 117, 12438-12448.

51 M. J. Frisch, G. W. Trucks, H. B. Schlegel, G. E. Scuseria, M. A. Robb, J. R. Cheeseman, G. Scalmani, V. Barone, B. Mennucci, G. A. Petersson, H. Nakatsuji, M. Caricato, X. Li, H. P. Hratchian, A. F. Izmaylov, J. Bloino, G. Zheng, J. L. Sonnenberg, M. Hada, M. Ehara, K. Toyota, R. Fukuda, J. Hasegawa, M. Ishida, T. Nakajima, Y. Honda, O. Kitao, H. Nakai, T. Vreven, J. A. Montgomery Jr J. E. Peralta, F. Ogliaro, M. Bearpark, J. J. Heyd, E. Brothers, K. N. Kudin, V. N. Staroverov, R. Kobayashi, J. Normand, K. Raghavachari, A. Rendell, J. C. Burant, S. S. Iyengar, J. Tomasi, M. Cossi, N. Rega, J. M. Millam, M. Klene, J. E. Knox, J. B. Cross, V. Bakken, C. Adamo, J. Jaramillo, R. Gomperts, R. E. Stratmann, O. Yazyev, A. J. Austin, R. Cammi, C. Pomelli, J. W. Ochterski, R. L. Martin, K. Morokuma, V. G. Zakrzewski, G. A. Voth, P. Salvador, J. J. Dannenberg, S. Dapprich, A. D. Daniels, 
Ö. Farkas, J. B. Foresman, J. V. Ortiz, J. Cioslowski and D. J. Fox, Gaussian 09, Revision A.02, Gaussian, Inc., Wallingford CT, 2009.

52 A. D. Becke, Phys. Rev. A: At., Mol., Opt. Phys., 1988, 38, 30983100.
53 C. Lee, W. Yang and R. G. Parr, Phys. Rev. B: Condens. Matter Mater. Phys., 1988, 37, 785-789.

54 A. D. Becke, J. Chem. Phys., 1993, 98, 5648-5652.

55 E. A. Cobar, R. Z. Khaliullin, R. G. Bergman and M. HeadGordon, Proc. Natl. Acad. Sci. U. S. A., 2007, 104, 6963-6968. 